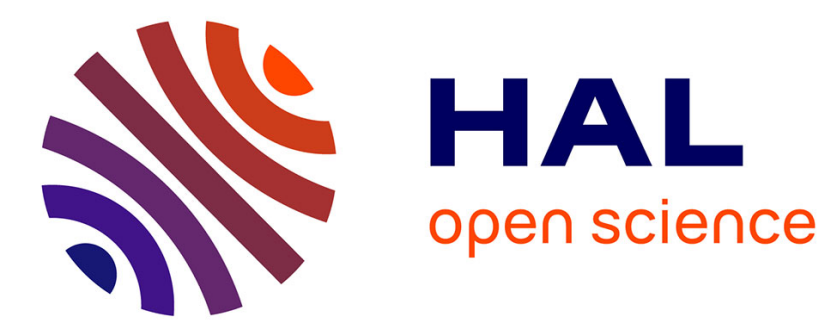

\title{
Intraorganizational Respect and Organizational Participation: The Mediating Role of Collective Identity
}

Stefan Stürmer, Bernd Simon, Michael I. Loewy

\section{To cite this version:}

Stefan Stürmer, Bernd Simon, Michael I. Loewy. Intraorganizational Respect and Organizational Participation: The Mediating Role of Collective Identity. Group Processes and Intergroup Relations, 2008, 11 (1), pp.5-20. 10.1177/1368430207084842 . hal-00571673

\section{HAL Id: hal-00571673 https://hal.science/hal-00571673}

Submitted on 1 Mar 2011

HAL is a multi-disciplinary open access archive for the deposit and dissemination of scientific research documents, whether they are published or not. The documents may come from teaching and research institutions in France or abroad, or from public or private research centers.
L'archive ouverte pluridisciplinaire HAL, est destinée au dépôt et à la diffusion de documents scientifiques de niveau recherche, publiés ou non, émanant des établissements d'enseignement et de recherche français ou étrangers, des laboratoires publics ou privés. 


\title{
Intraorganizational Respect and Organizational Participation: The Mediating Role of Collective Identity
}

\author{
Stefan Stürmer \\ FernUniversität in Hagen \\ Bernd Simon \\ Christian-Albrechts-Universität zu Kiel \\ Michael I. Loewy \\ University of North Dakota
}

\begin{abstract}
A panel study with two points of measurement throughout a four-month interval $(N=189)$ in the context of a socio-political organization was conducted to examine the role of collective identity in mediating the relationship between perceived respect and organizational participation. Path analyses confirmed that the effect of perceived respect at Time 1 on organizational participation at Time 2 was fully mediated by the cognitive component of collective identity ('importance-to-identity'). Interestingly, although perceived respect at Time 1 also had a significant effect on the evaluative component of collective identity ('private collective self-esteem'), this component was not involved in the mediation. Including perceived individual benefits as statistical controls in the model did not change this picture. In fact, with regard to the link between perceived benefits and participation results also point to a mediating role of the cognitive component of collective identity. Theoretical and practical implications of these findings are discussed.
\end{abstract}

KEYWORDS collective identity, intragroup respect, organizational participation

RESEARCH has demonstrated that feeling respected by group authorities or fellow group members strengthens group members' efforts to contribute to the group's welfare and the achievement of its goals (e.g. Branscombe, Spears, Ellemers, \& Doosje, 2002; Simon \& Stürmer, 2003; Smith, Tyler, Huo, Ortiz, \& Lind, 1998; Tyler \& Blader, 2000). The present research concerns the 'psychology' underlying this effect. Specifically, we conducted a panel study in the context of a non-profit socio-political organization, in which we investigated whether and to what extent

\footnotetext{
$\overline{\text { Author's note }}$

Address correspondence to Stefan Stürmer, Institut für Psychologie, FernUniversität in Hagen, 58084 Hagen, Germany [email: stefan.stuermer@FernUni-Hagen.de]
} 
perceived intragroup (or organizational) respect affected members' subsequent identification with the target organization and their organizational participation. We also explored whether and to what extent organizational identification mediated the effect of respect on organizational participation. Alternative accounts of participation in this context emphasizing the role of perceived individual benefits (see, for instance, Clary et al., 1998) will also be addressed.

\section{A social identity analysis on the relationship between respect and group-oriented behavior}

The social identity approach, which first became known as social identity theory (Tajfel \& Turner, 1986) and was later further developed into self-categorization theory (Turner, Hogg, Oakes, Reicher, \& Wetherell, 1987), has directed researchers' attention to the pivotal role of selfcategorization or self-interpretation processes in regulating social behavior (Haslam, 2001; Hogg \& Abrams, 1996; Simon, 2004). A key distinction is made between personal or individual identity (i.e. self-interpretation as a unique individual) and social or collective identity (i.e. selfinterpretation in terms of group membership). The social identity approach suggests that selfinterpretation in terms of collective identity fosters internalization of in-group norms, values and interests (e.g. Haslam, 2001). Collective norms, values and interests are incorporated in the self and thus become prescriptive for one's behavior. Accordingly, group members with a strong sense of collective identity should be particularly motivated to behave as a 'good' group member and to contribute to the group's welfare (Stürmer, Simon, Loewy, \& Jörger, 2003).

Meanwhile, there exists a solid body of empirical work corroborating these assumptions. For instance, several studies show that when people define themselves in terms of their group membership they are more willing to take less from common resources and to contribute more to the collective good (e.g. Brewer \& Kramer, 1986; Kramer \& Brewer, 1984; van Vugt \& De Cremer, 1999). Highly identified group members are those that stand up and fight discrimination and injustices against their ingroup even if this behavior entails considerable personal costs (e.g. De Weerd \& Klandermans, 1999; Kelly \& Breinlinger, 1996; Simon et al., 1998; Stürmer \& Simon, 2004). Moreover, high-identifiers are also more likely than low identifiers to engage in collective helping such as community volunteerism or assisting group members that are worse off (e.g. Omoto \& Crain, 1995; Omoto \& Snyder, 2002; Simon, Stürmer \& Steffens, 2000; Stürmer \& Kampmeier, 2003).

The present research builds upon the assumption that respectful treatment by fellow group members strengthens self-interpretation in terms of collective identity. The theoretical rationale for this assumption is as follows. According to the social identity approach, common group membership induces perceived exchangeability of group members which typically entails expectations of fair and equal, if not favorable, treatment by fellow group members (Wenzel, 2004). Respectful treatment, which is in accordance with such expectations, is therefore likely to signal to the recipient that he or she is recognized as an equal group member ('I am treated like them because I am one of them'), thereby intensifying the link between the self and the in-group (Emler \& Hopkins, 1990; Simon, Lücken, \& Stürmer, 2006; Simon \& Stürmer, 2005; Tyler \& Smith, 1999). Turning to the effect of respectful treatment on grouporiented behavior, it is thus plausible to assume that one way that respectful treatment fosters group members' efforts on behalf of the group is by strengthening their sense of collective identity.

Direct empirical evidence for this hypothesis comes from a recent laboratory experiment in which manipulating respectful treatment affected both collective identification as well as willingness to cooperate for the realization of group goals (Simon \& Stürmer, 2003, also Simon \& Stürmer, 2005). The experiment was allegedly concerned with cooperation in virtual (computermediated) groups. Research participants (university students) worked separately on a common task (developing suggestions how to improve teaching and education at their university and 
designing collectively a poster presenting these suggestions to university officials). Communication between group members took place via electronic mail. Respectful versus disrespectful intragroup treatment was manipulated by way of (dis) respectful commentaries allegedly made by fellow group members concerning participants' contribution to the group task with commentaries phrased to convey fairness, neutrality and politeness or the opposite qualities. To give an example, in the respectful treatment conditions participants received commentaries such as, 'Thanks for your suggestions. You can be sure that I will take the time to think about them thoroughly'; in the disrespectful treatment, participants received commentaries such as 'Your suggestions have arrived. I just eye-balled them. Well, that's what I have to do, but actually, I am not so much interested in them' (for a similar experimental approach, see Smith et al., 1998). Further, the experiment also included a manipulation of explicit positive or negative overall performance evaluation in the form of grades ranging from 'excellent' to 'very bad' assigned by the same fellow members. In line with predictions, respectful as opposed to disrespectful treatment by fellow group members increased both group members' collective identification and their willingness to contribute to the realization of the group's goals. This effect was independent of explicit evaluation. In fact, respectful treatment fostered collective identification and willingness to contribute to group goals even under conditions where participants received negative performance evaluations from fellow members. Of particular interest, mediational analyses confirmed that the effect of perceived respect on group members' willingness to engage on behalf of the group was mediated by way of strengthening group members' collective identification.

\section{The present research}

To substantiate the hypothesized relationships between respect, identification and grouporiented behavior in a naturalistic field setting, we conducted a panel field study with members of the National Association to Advance Fat
Acceptance (NAAFA), ${ }^{1}$ a non-profit organization in the context of the US fat acceptance movement. The overarching objectives of NAAFA are fighting discrimination against fat people and promoting contact and solidarity among fat people. To realize these goals, NAAFA members volunteer in a variety of domains such as planning meetings or campaigns, organizing special task forces, or fund raising (see www.naafa.org).

To test our theoretical perspective in this context we pursued the following analytical strategies. First, we examined whether perceived respectful treatment by fellow NAAFA members measured at Time 1 predicted the strength of respondents' subsequent organizational identification measured at Time 2, four months later. Second, we tested whether perceived respect measured at Time 1 also predicted respondents' self-reported organizational participation at Time 2. Although self-report measures of participation are not perfect, they are generally satisfactory indicators of actual participation (Fullagar, 1986; Klandermans, 1997). Third, we examined whether and to what extent the effect of Time 1 perceived respect on Time 2 organizational participation was mediated by way of collective identification with the target organization.

To further strengthen the interpretation of our findings we incorporated the following features in our research design. First, we examined the role of different identity components in mediating the respect effect. Collective identity is a multidimensional construct comprising both cognitive and evaluative components (Jackson \& Smith, 1999). Meanwhile, there exists increasing empirical evidence that different components of collective identity may be differentially involved in the prediction of group related attitudes and behaviors (e.g. Ellemers, Kortekaas, \& Ouwerkerk, 1999; Jackson, 2002; van Dick, Wagner, Stellmacher, \& Christ, 2004). Still, when and why one component has greater predictive value than another remains an undertheorized issue. Our theoretical analysis suggests that one particularly likely way of how perceived respect is effective is by way of strengthening the cognitive component of collective identity (i.e. the degree to which the group or organization is 
self-defining). As the relevance of organizational membership for the self-concept increases, group norms and standards should become incorporated into the self; this, in turn, should increase the likelihood that group members behave in accordance with organizational standards and contribute to organizational goals (Haslam, 2001; Stürmer et al., 2003). In fact, data collected in a previous field study in the context of the German gay movement (Stürmer \& Simon, 2004) using a similar panel design and employing equivalent measures of organizational participation also point to a pivotal role of the cognitive component of collective identity. Specifically, multiple regression analyses (reported in Stürmer, 2000) in which we explored the relative contribution of measures capturing the cognitive component and measures capturing the evaluative component of collective identification with a social movement organization revealed that only the cognitive component contributed to the prediction of organizational participation, while the contribution of the evaluative component was nonsignificant. Building on this theoretical and empirical evidence we were thus inclined to expect that the cognitive component of collective identity would play an important role in mediating the effect of respect on organizational participation. Still, other work suggests that the evaluative component of collective identity, too, may be involved in this mediation. Specifically, this research suggests that perceived respectful treatment affects group members' collective self-esteem (or pride) they associate with their group membership. Feelings of collective selfesteem may set in motion additional motivating processes, such as esteem-enhancement or maintenance, which may also stimulate organizational participation (Smith \& Tyler, 1997; Tyler, Degoey, \& Smith, 1996). In fact, the laboratory research by Simon and Stürmer (2003) also provided evidence that in addition to the cognitive component of collective identity, the evaluative component was also involved in mediating the effect of intragroup respect on group members' willingness to engage on behalf of the group. To precisely delineate in the present study whether the respect effect on organizational participation results from strengthening the self-definition in terms of group membership (i.e. the importance of group membership to one's self-concept) or from increasing positive feelings associated with membership in NAAFA (i.e. collective selfesteem), or both, we systematically measured both components of collective identity and compared their potential mediating role.

Another feature of our design concerned the interpretation of the respect effect. Specifically, to conceptually isolate the effects of this variable, we also examined whether the expected effects on collective identity and/or organizational participation held up even when we controlled for additional potentially relevant predictors of these criteria. A resource-based theory of group behavior (e.g. Rusbult \& van Lange, 1996) suggests that group-related individual benefits may increase both attachment to the group and participation in group-oriented activities (see also Sleebos, Ellemers \& de Gilder, 2006, and Tropp \& Brown, 2004, for more detailed discussions of individualistic routes to grouporiented behavior). In other words, NAAFA members may identify with NAAFA, and likewise participate in joint activities with fellow NAAFA members, because they expect to gain (or actually gain) specific knowledge, skills, or social contacts which are important to specific personal needs. To demonstrate the unique explanatory power of perceived respect above and beyond such individual benefits of participation, we systematically assessed potential individual benefits linked to organizational participation in the present context with an established inventory (the Volunteer Functions Inventory; Clary et al., 1998) and included this measure as a statistical control variable in our analyses (for a similar approach, see Tyler \& Blader, 2000).

\section{Method}

\section{Procedure}

Data were collected from registered members of one of the largest formal organizations in the context of the fat acceptance movement, the National Association to Advance Fat Acceptance (NAAFA). At the time of our survey, NAAFA membership was predominantly female (with 
less than $10 \%$ male members). At Time 1 and Time 2 (4 months later) we sent out standardized questionnaires by mail to all registered members of NAAFA $(N=1,530)$. At both time points respondents returned the completed questionnaire in a prepaid and addressed envelope. A cover letter introduced the study as part of a research project concerned with fat people's motives for joining organizations that represent the interests of fat people. In addition, the authors expressed their gratitude to NAAFA's board of directors and staff for their support in carrying out this investigation.

To increase the response rate at Time 1 we offered to donate US $\$ 1$ to NAAFA for each completed and returned questionnaire. At Time 2 we promised a donation of US $\$ 250$ to NAAFA if more than 500 NAAFA members participated. Additionally, all respondents participated in a lottery in which they could win a prize of US $\$ 100$. Respondents were promised and given two lottery tickets if they had also participated at Time 1.

To match responses at Time 1 and Time 2, while still ensuring anonymity, respondents were asked in both questionnaires to assign themselves an individualized five-letter code along several specified criteria (e.g. second letter of mother's first name). At both points of measurement response rates were adequate and in line with other anonymous mail surveys reported in the literature (e.g. Kelly \& Breinlinger, 1996; Stürmer \& Simon, 2004). Altogether, 503 NAAFA members returned the Time 1 questionnaire (response rate $=33 \%$ ). At Time 2 a total of 339 questionnaires were returned (response rate $=22 \%)$. At both Times 1 and 2, 206 NAAFA members returned the questionnaire. Missing data analyses revealed that 17 of the respondents who participated at both points in time could not be included in the panel analyses because they skipped substantial parts of the questionnaires. This resulted in a panel sample of 189 respondents.

\section{Measures}

Perceived intragroup respect (measured Time 1 and Time 2) To measure the degree to which respondents' felt treated respectfully by other
NAAFA members at the first point of measurement (the main predictor variable of the present research) we adapted five items from the respect scale developed by Smith and Tyler (1997): (1) I believe that other members of NAAFA react well to me, to what I say and do; (2) Currently, most members of NAAFA who know me respect me; (3) I often feel that I am a useless member of NAAFA (reverse scored); (4) If they knew me well, members of NAAFA would respect my values; and (5) If they knew me well, members of NAAFA would respect how I live my life. Respondents made their ratings on 7-point scales ranging from 0 (not true at all) to 6 (completely true). For each respondent, we calculated a single index by averaging responses over the five items (Cronbach's $\alpha=.74$ ). As we were also interested in gathering information about how respected participants felt at the second point of measurement, we included a subset of the items used at Time 1 in the Time 2 questionnaire (items 1 to 3). For each respondent, we calculated a single index for respect reported at Time 2 by averaging over these items (Cronbach's $\alpha=.75$ ).

\section{Collective identity (measured Time 1 and Time 2)}

We measured two distinct but related components of collective identity. First, to measure the degree to which membership in NAAFA was self-defining (i.e. the cognitive component of collective identity) we used the four-item importance-to-identity subscale of Luhtanen and Crocker's (1992) Collective Self-Esteem Scale with each of the four items reworded to refer to membership in NAAFA (e.g. 'Belonging to NAAFA is an important part of my selfimage'). Second, to measure respondents' feelings of collective esteem associated with their organizational membership (i.e. the evaluative component of collective identity) we used the four-item private collective self-esteem subscale of Luhtanen and Crocker's measure (1992). Again, all items were reworded in terms of NAAFA identity (e.g. 'In general, I'm glad to be a member of NAAFA'). Adaptations of the importance-to-identity and private collective self-esteem subscales are frequently used to measure cognitive and evaluative aspects of 
collective identity (e.g. Ethier \& Deaux, 1994; for an overview, see Jackson \& Smith, 1999). Respondents completed both scales at each point of measurement. Ratings were made on 7-point scales ranging from 0 (not true at all) to 6 (completely true). For each point of measurement, principal component analyses with subsequent varimax rotation confirmed a clear two-factor solution corresponding to the two subscales. Accordingly, we calculated for each respondent separate single indexes for importance-to-identity and private collective self-esteem at Time 1 and Time 2 by averaging responses over the four items (importance-to identity: Cronbach's $\alpha=.90$ for Time 1, and .86 for Time 2, private collective self-esteem: Cronbach's $\alpha=.78$ for Time 1 , and .80 for Time 2$).^{2}$

Perceived individual benefits of participation (measured Time 1) To measure the perceived individual benefits of participation (the control variables in the present research) we adapted Clary et al.'s (1998) Volunteer Function Inventory. This inventory consists of six 5-item subscales; each subscale relates to one specific class of individual benefits linked to volunteering. Participants were carefully instructed to respond to each item with regard to volunteering in the context of NAAFA. These benefits are (a) ego-protection (e.g. 'Volunteering is a good escape from my troubles'), (b) expressing values (e.g. 'I feel it is important to me to help others'), (c) career-related benefits (e.g. 'I can make new contacts that might help my business or career'), (d) social integration (e.g. 'Others with whom I am close place a high value on community service'), (e) gaining understanding (e.g. 'Volunteering allows me to gain a new perspective on things'), and (f) enhancing self-esteem (e.g. 'Volunteering increases my self-esteem'). Ratings were made on 7-point scales ranging from 0 (not true at all) to 6 (completely true). For each respondent, we computed an 'overall' score for the perceived individual benefits by averaging over the 30 items (Cronbach's $\alpha=.92$ ). In addition, for each respondent we also computed a single index score for each of the six subscales (Cronbach's $\alpha \geq .79$ ).
Organizational participation (measured at Time 1 and Time 2) At Time 1, respondents provided information about their previous involvement in NAAFA. Specifically, they indicated (yes [1] or no [0]) whether or not they had actively participated in the following voluntary activities within the last 12 months: (1) attending NAAFA meetings and conventions; (2) participating in special interest groups and chapter meetings; (3) assuming office in NAAFA (e.g. national or chapter leader); (4) helping to organize campaigns (e.g. demonstrations, International No Diet Day); (5) fund raising for NAAFA; and (6) participating in other activities to be specified by the respondent. At Time 2 respondents indicated (yes [1] or no [0]) whether or not they had actively participated in the activities listed above in the 4-month period between the first and the second point of measurement. We calculated for each respondent separate sum totals for her or his participation in the six activities at Time 1 and at Time 2 (Cronbach's $\alpha=.78$ for Time 1, and .80 for Time 2). Scores for organizational participation can thus vary between 0 and 6 .

At both time points questionnaires included additional items which are not directly relevant for this report and are therefore not discussed further. On the last pages of each questionnaire, respondents provided sociodemographic data such as age, education and occupation. Through a question included at the end of the questionnaires we checked that none of the respondents completed more than one questionnaire at a time point.

\section{Results}

\section{Sociodemographic data}

The panel sample included 163 women and 13 men, 13 respondents did not indicate their gender. ${ }^{3}$ Respondents' age ranged from 22 to 72 years, with a mean age of 45.10 years $(S D=9.74$ years, 1 respondent did not provide information about her age). Most respondents indicated that they had a college degree $(n=116)$ or trade or technical school degrees $(n=53)$; the remaining respondents had completed high school $(n=12)$ or junior high school $(n=3)$ or did not provide 
information about their education $(n=5)$. A total of 131 respondents worked full-time in various fields including the business sector, social services, teaching institutions or arts and media; 13 respondents worked part-time; 12 were retired, 9 were unable to work because of a disability, 6 respondents were currently unemployed, 4 respondents were housewives; 1 was a student, the remaining respondents did not provide information about their occupation. Seventy-five respondents indicated that they were married or in long-term relationships, the remaining respondents were single $(n=77)$, divorced $(n=28)$, or widowed $(n=4)$, five respondents did not respond to this item or indicated that the specified categories did not apply to them.

\section{Responsiveness analyses}

We compared the respondents included in the panel sample $(N=189)$ with the NAAFA members who responded only at one time point (i.e. the 297 'drop outs' who did not continue their participation in the study at Time 2) with regard to all theoretically relevant variables measured at Time 1 (perceived respect, importanceto-identity, collective self-esteem, individual benefits, past participation). In addition, we compared the panel sample with the 133 'new' respondents who participated only at Time 2 with regard to all theoretically relevant variables measured at Time 2 (perceived respect, collective identification, subsequent participation). (Note that for simplicity, all statistical tests are reported two-tailed, even for directional predictions.) The analyses produced three significant findings (for all other tests $p \mathrm{~s} \geq .22$ ). Respondents included in the panel sample felt somewhat more respected than did respondents who participated only at Time $1(M(189)=4.33, S D=0.99$ vs. $M(292)=4.10, S D=1.23 ; t(456.14, d f$ for $t$-test with unequal variances $)=2.32, p=.021)$. Likewise, respondents in the panel sample scored higher on the importance-to-identity scale than did respondents who participated only at Time $1(M(189)=3.23, S D=1.63$ vs. $M(295)=2.90, S D=1.66, t(482)=2.15$, $p=.032)$; and they reported higher levels of private collective self-esteem $(M(189)=4.89$, $S D=0.92$ vs. $M(297)=4.59, S D=1.21, t(468.54)=$ $3.17, p=.002)$. These findings are interesting in themselves because they fall clearly in line with the perspective tested in this article. Apparently, those who felt respected and identified with the organization were particularly motivated to act in terms of their identity as 'good' (cooperative) NAAFA members-to contribute to research that was supported by NAAFA's board of directors and staff.

\section{Correlational analyses}

Table 1 presents the means, standard deviations and intercorrelations for all relevant variables. Our theoretical analysis suggests that perceived respect affects organizational participation by way of strengthening organizational identification. In line with this mediational hypothesis, perceived respect at Time 1 (the 'independent variable') was a significant predictor of the two identity components measured at Time 2 (the potential mediators) as well as organizational participation at Time 2 (the 'dependent variable'). In addition, and also in line with predictions, the two identification components measured at Time 2 were significantly correlated with organizational participation at Time 2 (all $p \mathrm{~s} \leq .027){ }^{4}$

\section{Path analyses: The mediating role of collective identity}

In order to examine the role that collective identity plays in mediating the effect of respect at Time 1 on organizational participation at Time 2 a series of path analyses with observed variables using LISREL 8.50 were conducted. To provide a particularly rigorous test of our perspective, we controlled in our analyses for respondents' Time 1 values of the dependent variable (organizational participation at Time 2). By controlling for 'baseline' estimates of the dependent variable, we thus effectively tested the predictive value of perceived respect and collective identification with regard to changes (i.e. residual gains) in organizational participation in the period between the two points of measurement (for a discussion of residual 
Table 1. Intercorrelations, means and standard deviations for perceived respect, identity components, individual benefits and organizational participation measured at Time 1, and perceived respect, identity components, and organizational participation measured at Time 2

\begin{tabular}{|c|c|c|c|c|c|c|c|c|c|c|c|}
\hline Variables & $M$ & $S D$ & 1 & 2 & 3 & 4 & 5 & 6 & 7 & 8 & 9 \\
\hline $\begin{array}{l}\text { 1. Perceived respect } \\
\text { (Time 1) }\end{array}$ & 4.33 & 0.99 & - & $.29 * * *$ & $.29 * * *$ & $.21 * *$ & $.36^{* * * *}$ & $.61 * * *$ & $.32 * * *$ & $.34 * * *$ & $.37 * * *$ \\
\hline $\begin{array}{l}\text { 2. Importance-to- } \\
\text { identity (Time 1) }\end{array}$ & 3.23 & 1.63 & & - & $.54 * * *$ & $.38 * * *$ & $.18^{*}$ & $.23 * *$ & $.78 * * *$ & $.46^{* * * *}$ & $.29 * * *$ \\
\hline $\begin{array}{l}\text { 3. Private collective } \\
\text { self-esteem (Time 1) }\end{array}$ & 4.89 & 0.92 & & & - & $.29 * * *$ & -.06 & $.15^{*}$ & $.48 * * *$ & $.75 * * *$ & -.00 \\
\hline $\begin{array}{l}\text { 4. Individual benefits } \\
\text { (Time 1) }\end{array}$ & 3.57 & 0.93 & & & & - & $.26^{* * *}$ & $.21 * *$ & $.33 * * *$ & $.27 * * *$ & $.23 * *$ \\
\hline $\begin{array}{l}\text { 5. Organizational } \\
\text { participation (Time 1) }\end{array}$ & 1.32 & 1.65 & & & & & - & $.47 * * *$ & $.16^{*}$ & .12 & $.79 * * *$ \\
\hline $\begin{array}{l}\text { 6. Perceived respect } \\
\text { (Time 2) }\end{array}$ & 3.56 & 1.53 & & & & & & - & $.29 * * *$ & $.32 * * *$ & $.49 * * *$ \\
\hline $\begin{array}{l}\text { 7. Importance-to- } \\
\text { identity (Time 2) }\end{array}$ & 3.26 & 1.57 & & & & & & & - & $.54 * * *$ & $.25 * *$ \\
\hline $\begin{array}{l}\text { 8. Private collective } \\
\text { self-esteem (Time 2) }\end{array}$ & 4.94 & 1.03 & & & & & & & & - & $.16^{*}$ \\
\hline $\begin{array}{l}\text { 9. Organizational } \\
\text { participation (Time 2) }\end{array}$ & 1.41 & 1.69 & & & & & & & & & - \\
\hline
\end{tabular}

$* p<.05 ; * * p<.01 ; * * * p<.001$ (two-tailed).

Notes: Statistics are based on the panel sample $(N=189)$. Scores for variables can vary between 0 and 6 , with higher scores indicating more perceived respect, stronger importance-to-identity, higher private collective self-esteem, greater perceived benefits, and greater self-reported participation.

gains as estimates of change, see Cronbach \& Furby, 1970).

To test the mediating role of the two collective identity components in the respect-organizationalparticipation relationship we compared two competing models with regard to their goodness of fit to the data (Hoyle, 1995). In the first model, assuming full mediation, perceived respect at Time 1 was only indirectly related to organizational participation at Time 2 through its effects on the two identity components measured at Time 2; in the second model an additional direct path from respect at Time 1 to organizational participation at Time 2 was added. Full mediation is shown when (a) the indirect effect of the independent variable (perceived respect at Time 1) on the dependent variable (organizational participation at Time 2) via the assumed mediator(s) (the cognitive and/or evaluative components of collective identity measured at Time 2) is significant, and (b) adding a direct path between the independent and the dependent variable does not significantly improve the model's fit to the data (Hoyle, 1995, also Kenny, Kashy, \& Bolger, 1998). In both models, since the potential mediators represent components of the same underlying construct (collective identity), we allowed their error terms to co-vary.

Model 1, proposing full mediation of the respect effect, fit the data very well, $\chi^{2}(3)=2.71$, $p=.439$, goodness of fit index $(\mathrm{GFI})=.99$, comparative fit index $(\mathrm{CFI})=1.00$, root mean square error of approximation (RMSEA) $=.00$. (Note that a nonsignificant $\chi^{2}$ is indicative for a satisfying model fit.) The standardized solution for this model is shown in Figure 1. In line with the assumed mediational relationship, perceived respect at Time 1 had a direct effect on the cognitive component of collective identity measured at Time 2, which, in turn, had a significant direct effect on organizational participation at Time 2. Moreover, confirming the mediating role of the cognitive component of 


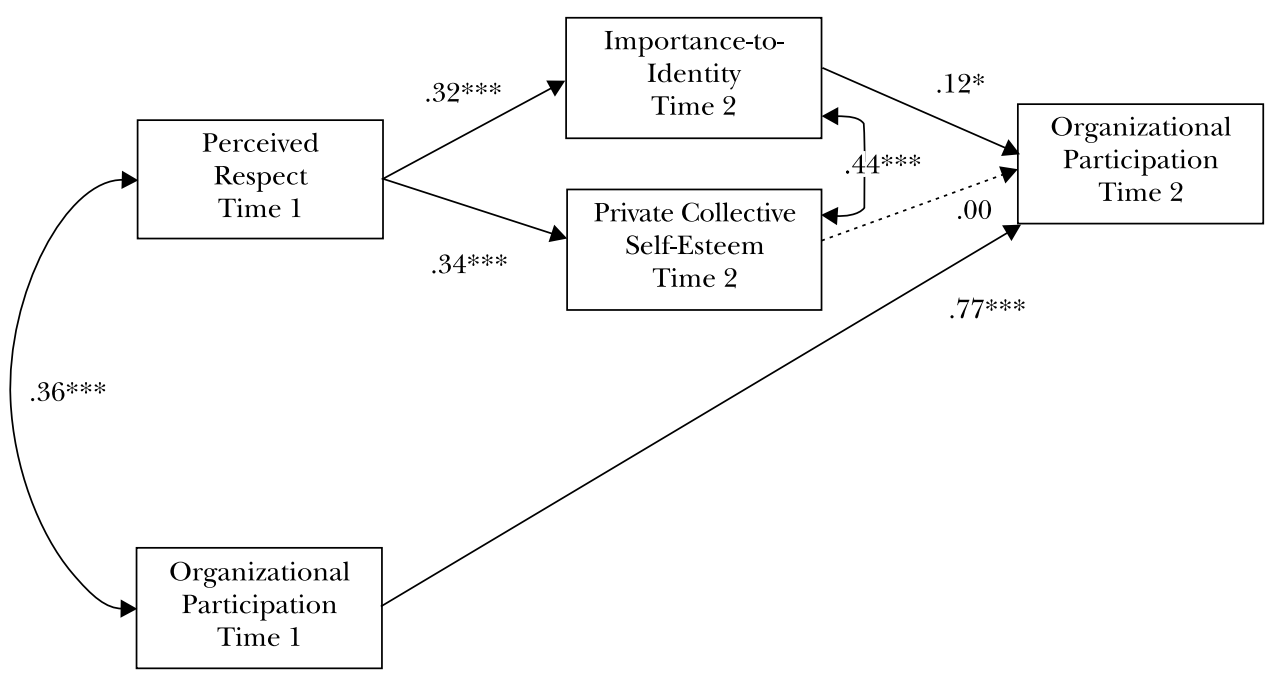

Figure 1. Full mediation model with organizational participation at Time 1 as control variable (standardized solution).

$* p<.05 ; * * * p<.001$ (two-tailed).

collective identity, the indirect effect of perceived respect at Time 1 on organizational participation at Time 2 via the cognitive component measured at Time 2 was significant (indirect effect $=.04$, $z=2.06, p=.040)$. Interestingly, however, although perceived respect at Time 1 had also a direct effect on the evaluative component of collective identity measured at Time 2 , this component did not affect organizational participation at Time 2. Hence, unlike the cognitive component of collective identity the evaluative component was not involved in mediating the effect of perceived respect on organizational participation (indirect effect $=.00, z=0.80$, $p=.936)$. The more restrictive model omitting the nonsignificant path from the evaluative component to organizational participation at Time 2 still provided excellent fit to the data $\left(\chi^{2}(4)=2.72, p=.606, \mathrm{GFI}=.99, \mathrm{CFI}=1.00\right.$, RMSEA $=.00)$.

Comparing the fit of Model 1 with the fit of Model $2\left(\chi^{2}(2)=0.66, p=.718\right.$, GFI $=1.00$, $\mathrm{CFI}=1.00$, RMSEA $=.00)$, that included an additional direct path between perceived respect at Time 1 and organizational participation at Time $2(\beta=.07, t(184)=1.42, p=.158)$, by using a $\chi^{2}$ difference test (Hoyle, 1995) did not reveal a significant goodness of fit difference $\left(\Delta \chi^{2}(1)=2.05, p=.152\right)$. This corroborates the assumption that the effect of perceived respect at Time 1 on organizational participation at Time 2 was in fact fully mediated by collective identity, or more specifically, its cognitive component.

\section{Controlling for Individual Benefits of Participation}

A resource-based theory of group behavior (e.g. Rusbult \& van Lange, 1996) suggests that group related individual benefits may increase both attachment to the group as well as participation in group-oriented activities. In fact, the perceived individual benefits measure (Time 1) was a significant predictor of the two identification components (Time 2) as well as of organizational participation at Time $2(r \mathrm{~s} \geq .23$, $p$ s $\leq .002)$ (see Table 1 ). To examine whether the effects of perceived respect and collective identity (i.e. its cognitive component) reported in Figure 1 held up even when we controlled for perceived individual benefits of participation, we computed a series of additional path models in which we included the perceived individual benefits measure as an additional predictor. In a first step, we included any possible path from 
individual benefits to the endogenous variables (identity components at Time 2 , organizational participation at Time 2). However, as the path from perceived individual benefits to organizational participation at Time 2 turned out to be nonsignificant $(\beta=-.01, t(183)=-0.28, p=.780)$, this path was dropped in the final model. Figure 2 shows the standardized solution for the final model with perceived individual benefits included as an additional exogenous variable $\left(\chi^{2}(4)=2.63, p=.622, \mathrm{GFI}=1.00, \mathrm{CFI}=1.00\right.$, RMSEA $=.00)$. As can be seen, the effects of perceived respect at Time 1 and the cognitive component of collective identity (Time 2) held up even when we controlled for perceived individual benefits of participation. Moreover, the indirect effect of perceived respect at Time 1 on organizational participation at Time 2 via the cognitive component (Time 2) remained significant (indirect effect $=.03, z=1.97$, $p=.049)$. Note that including any further path did not result in significant improvements of the model's fit. The more restrictive model omitting the nonsignificant path from the evaluative component of collective identity to organizational participation at Time 2 still yielded excellent fit $\left(\chi^{2}(5)=2.64, p=.755, \mathrm{GFI}=1.00, \mathrm{CFI}=1.00\right.$, RMSEA $=.00)$.

Additional path analyses, in which we successively replaced the global benefits measure with each of the six 5-item subscales of this measure as control variable (see Method section for details) yielded a similar picture. In all analyses the direct effects of perceived respect and the cognitive component of collective identity reported in Figure 2 remained significant. The same was true for the indirect effect of perceived respect on organizational participation via the cognitive component. Moreover, while some of the individual benefits subscales emerged as significant predictors of the identity components none of them had a significant direct effect on organizational participation (all $p \mathrm{~s} \geq .282$ ).

To further substantiate the validity of the findings obtained in the mediational analyses, we reran all path analyses reported above using the Time 1 measures of the cognitive and the evaluative components of collective identity

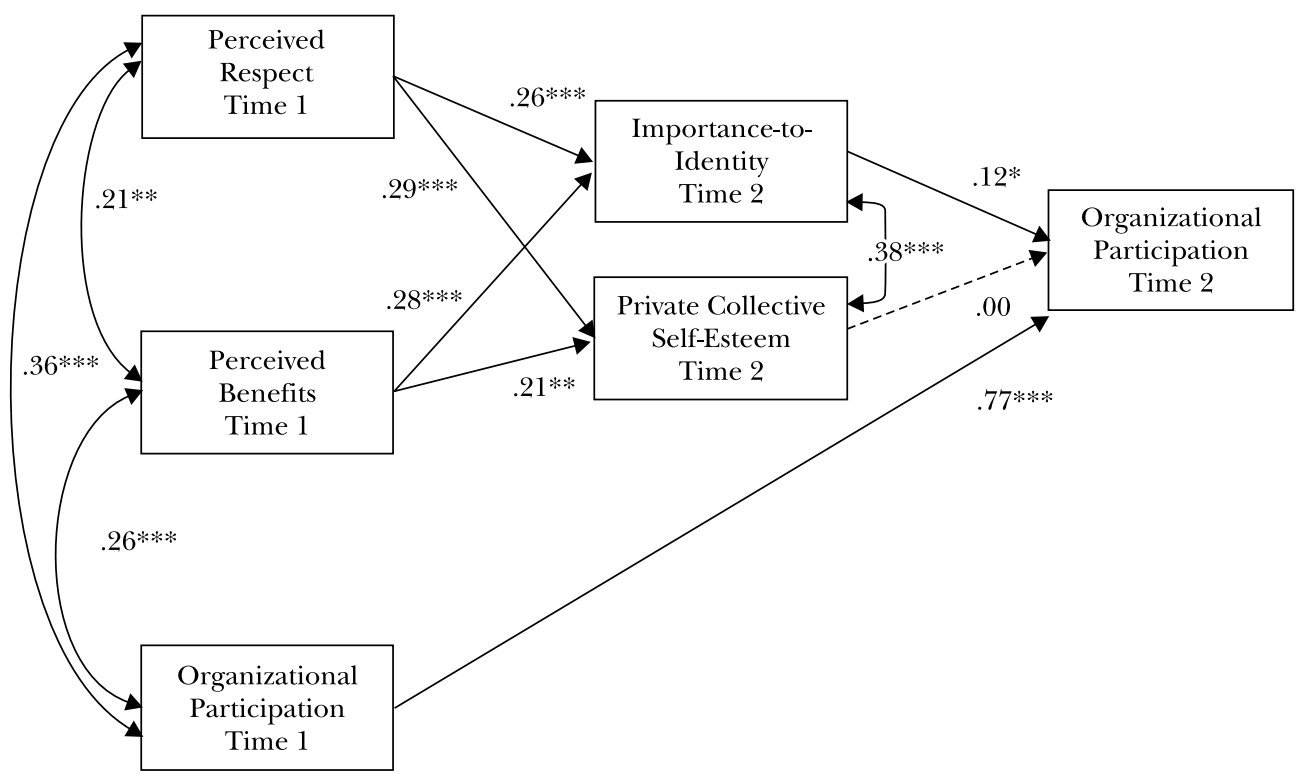

Figure 2. Full mediation model with organizational participation at Time 1 as control variable and perceived benefits at Time 1 as additional predictor (standardized solution).

$* p<.05 ; * * p<.01 ; * * * p<.001$ (two-tailed). 
instead of the Time 2 measures as the critical mediators. Using the Time 1 measures of the collective identity components as mediators replicated all relevant findings. The cognitive component measured at Time 1 also proved as a full mediator of the effect of perceived respect at Time 1 on organizational participation at Time 2 (indirect effect $=.04, z=2.39, p=.017$ ), while the evaluative component of collective identity measured at Time 1 was again not involved in mediating the respect effect (indirect effect $=-.01, z=1.09, p=.276$ ). Further, we also tested alternative causal models-a model with the two identity components measured at Time 2 and organizational participation at Time 2 as correlated, as opposed to the former causing the latter $\left(\chi^{2}(4)=5.03, p=.284\right)$, and a model assuming a 'reverse' causal relationship between collective identity components and organizational participation at Time 2 $\left(\chi^{2}(4)=7.86, p=.097\right)$. In comparison to the original model $\left(\chi^{2}(4)=2.63, p=.622\right)$, both models yielded higher $\chi^{2}$ values, indicating worse fit to the data. (All estimates from path models controlling for organizational participation at Time 1 and perceived individual benefits.) Taken together, these additional analyses thus further strengthened our confidence in the validity of the mediational model with the cognitive component of collective identity as the pivotal mediating variable.

\section{Additional analyses: Causal direction}

Our theoretical analysis focuses on the paths from perceived respect to collective identity and to organizational participation. However, reversed effects, such as 'feedback effects' from organizational participation on perceived respect or collective identity seem also possible. To explore the likelihood of such reversed effects, we also conducted a set of two-variable-two-wave crosslagged panel analyses (Heise, 1975). The results of these additional analyses are summarized in Table 2. As the evaluative component of collective identity was not involved in mediating the respect effect we focus this presentation on the cognitive component (importance-toidentity). As can be seen, in addition to the significant 'causal' effects predicted by our theoretical analysis-perceived respect at Time $1 \rightarrow$ importance-to-identity at Time 2 , perceived respect at Time $1 \rightarrow$ organizational participation at Time 2 , importance-to-identity at Time $1 \rightarrow$ organizational participation at Time 2 (all $t \mathrm{~s}(186) \geq 2.12, p \mathrm{~s} \leq .036)$-these analyses revealed only one significant 'feedback effect', namely an effect of organizational participation at Time 1 on perceived respect at Time 2

Table 2. Two-variable-two-wave cross-lagged panel analyses on perceived respect and the importance-toidentity component, perceived respect and organizational participation, and the importance-to-identity component and organizational participation

\begin{tabular}{|c|c|c|c|c|c|c|}
\hline & \multicolumn{2}{|c|}{$\begin{array}{c}\text { Synchronous } \\
\text { correlations }\end{array}$} & \multicolumn{2}{|c|}{$\begin{array}{c}\text { Stability } \\
\text { coefficients }^{\mathrm{a}}\end{array}$} & \multicolumn{2}{|c|}{$\begin{array}{l}\text { Cross-lagged } \\
\text { coefficients }^{\mathrm{a}}\end{array}$} \\
\hline & $r_{x 1 y 1}$ & $r_{x 2 y 2}$ & $\beta_{x 1 x 2}$ & $\beta_{y 1 y 2}$ & $\beta_{x 1 y 2}$ & $\beta_{y 1 x 2}$ \\
\hline \multicolumn{7}{|l|}{ Respect and importance-to-identity } \\
\hline Perceived respect $(x)$ & $.29 * * *$ & $.29 * * *$ & $.59 * * *$ & & $.10^{*}$ & \\
\hline Importance-to-identity $(y)$ & & & & $.75 * * *$ & & .06 \\
\hline \multicolumn{7}{|l|}{ Respect and participation } \\
\hline Perceived respect $(x)$ & $.36 * * *$ & $.49 * * *$ & $.51 * * *$ & & $.10^{*}$ & \\
\hline Organizational participation $(y)$ & & & & $.75 * * *$ & & $.28 * * *$ \\
\hline \multicolumn{7}{|c|}{ Importance-to-identity and participation } \\
\hline Importance-to-identity $(x)$ & $.18^{*}$ & $.25 * * *$ & $.77 * * *$ & & $.15 * *$ & \\
\hline Organizational participation $(y)$ & & & & $.76 * * *$ & & .02 \\
\hline
\end{tabular}


$(t(186)=4.81, p<.001)$. The effects of importanceto-identity at Time 1 on perceived respect at Time 2, or of organizational participation at Time 1 on importance-to-identity at Time 2 were both nonsignificant $(t \mathrm{~s}(186) \leq 0.99, p \mathrm{~s} \geq$ .322). The significant effect of organizational participation at Time 1 on perceived respect at Time 2 points to the dynamic and reciprocal causal relationship between feelings of respect and organizational participation. On the one hand, as depicted in Figure 1, feeling respected by fellow organizational members promotes organizational participation by way of strengthening the degree to which the group is self-defining. On the other hand, engaging in behavior serving one's organization feeds back on members' perception of how respected they are.

\section{Discussion}

Building on previous research (e.g. Branscombe et al., 2002; Simon \& Stürmer, 2003; Smith et al., 1998; Tyler \& Blader, 2000) the present panel study investigated the role of perceived intraorganizational respect in organizational identification and organizational participation. Specifically, we examined whether and to what extent the facilitative effect of feeling respected by fellow organizational members on organizational participation can be explained by a mediating role of collective identity. To further advance our understanding of this mediational relationship, we systematically measured two distinct but related components of collective identity-the importance of group membership to one's self-concept and feelings of collective self-esteem-and compared their mediating role.

In line with predictions, cross-lagged correlations showed that perceived respect at Time 1 was a significant predictor of the two identity components measured at Time 2 as well as of organizational participation at Time 2. Moreover, and in support of the assumed mediation model, path analyses in which we controlled for respondents' Time 1 values of the dependent variable (organizational participation at Time 2) as well as for potentially alternative predictors (individual benefits) confirmed a significant indirect effect of perceived respect at Time 1 on organizational participation at Time 2 (or, more specifically, changes or residual gains in organizational participation) via the cognitive component of collective identity. Results suggest that the effect of perceived respect at Time 1 on changes in organizational participation was, in fact, completely mediated by the cognitive component of collective identity. Interestingly, although perceived respect at Time 1 also had a significant direct effect on the evaluative component of collective identity measured at Time 2, this component was not involved in the mediation. In fact, replicating previous analyses comparing the predictive value of the cognitive and evaluative identity components in a similar context of socio-political participation (Stürmer, 2000), the evaluative component was completely ineffective as a unique predictor of organizational participation at Time 2. Analyses using the Time 1 measures of the cognitive and the evaluative components of collective identity instead of the Time 2 measures as the critical mediators replicated these findings. In sum, then, the converging results of multiple analysesa significant cross-lagged effect of perceived respect on the cognitive component of collective identity even with controls of alternative predictors (individual benefits), the finding that the cognitive component predicted change in organizational participation (again with controls of alternative predictors), the finding of a significant and complete mediation of the effect of perceived respect on organizational participation via the cognitive component of collective identity-provide clear support for the proposition that intragroup respect fosters group-oriented behavior by way of strengthening the importance of group membership to one's self-concept (i.e. the cognitive component of collective identity).

The present data substantiate and extend the results from our previous laboratory research (Simon \& Stürmer, 2003) in a naturalistic field setting of group-oriented behavior. The perhaps most important extension of our laboratory findings concerns the differential role of the two components of collective identity investigated 
in the present context. While in the laboratory both the cognitive and evaluative component of collective identity played a role in mediating the effect of respect, in the present field study the evaluative component was ineffective as a mediator. The variation between our field and laboratory data underscores the value of a more comprehensive research strategy combining laboratory experimentation with replications in field research designs, specifically as it may help to detect important moderating factors of the effects under study. A potentially relevant conceptual difference between the laboratory setting and the setting of the present field study concerns the extent to which group members may have anticipated an evaluation of their ingroup's performance in achieving its goals. Specifically, unlike in the present study, in the laboratory research multiple virtual groups worked on similar tasks (developing suggestions on how to improve teaching and education at their university), creating a potential of between-group competition and performance evaluations. Research suggests that group members' collective self-esteem may play a role in shaping their perceptions and behaviors by setting in motion motivational processes, such as esteem-enhancement or maintenance, especially under intergroup conditions, involving potential threat to one's collective identity (e.g. Jackson, 2002). Accordingly, rather than 'dismissing' the evaluative component of collective identity on the basis of the present data as a potential mediator in the respect-behavior link, future research should systematically explore whether and to what extent the mediating role of this variable is moderated through contextual factors such as the presence or absence of intergroup competition or identity threat.

A further interesting finding concerns the role of perceived individual benefits in the present context. Our path analyses revealed that perceived individual benefits did not have a direct effect on organizational participation at Time 2 (or, more specifically, changes or residual gains in this variable). Still, given the significant direct effect of individual benefits on the cognitive component of collective identity measured at Time 2 and that this component was a significant predictor of organizational participation at Time 2 (see Figure 2), it can be concluded that individual benefits had a significant indirect effect on Time 2 organizational participation that was mediated by the cognitive component of collective identity. Indeed, the indirect effect of perceived individual benefits of participation on organizational participation at Time 2 via importance-toidentity at Time 2 was significant (indirect effect $=.03, z=1.97, p=.046)$. It thus appears that perceived individual benefits increased group members' participation in volunteer organizational activities only to the extent that they further intensified the link between the self and the group. Penner (2002) recently proposed a conceptual model of volunteerism and organizational citizenship behavior that integrated cost-benefit approaches (e.g. Clary et al., 1998) and role identity perspectives (e.g. Charng, Piliavin, \& Callero, 1988). This model holds that while perceived individual benefits are important antecedents to the decision to begin volunteering, the more one volunteers the more likely it is that one internalizes one's social role as a volunteer into the self-concept, so that eventually this role identity becomes the proximal cause of sustained volunteerism. Finding in the present study that perceived individual benefits did only indirectly, via the cognitive component of collective identity, affected organizational participation is generally consistent with this perspective. Still, since other research suggests that collective identity and individual benefits may also exert independent effects on socio-political participation (e.g. Stürmer \& Simon, 2004) further research on the interrelation between the two processes, and possible alterations of their relationships over time, is needed.

In closing, we also wish to outline some practical implications of our findings. Our research emphasizes a democratic view of group membership in which the respectful treatment of individual members is critical for an attractive and successful group life (see also Simon \& Stürmer, 2003). Building on this conception, socio-political organizations may be particularly interested in implementing organizational 
norms and procedures which foster respectful relationships among its members. Cross-lagged panel analyses in which we illuminated the causal direction of the relationships under study suggest that perceived respect does not only affect group members' future organizational participation, but that engaging in behavior serving one's organization may also feed back on their perception of how respected they are. One may assume that an important precondition for the latter to happen is that group members feel that their contributions and efforts are being recognized. Further investigations along the lines of the research reported here, including the question of what organizational procedures, or intragroup behaviors, members perceive as (dis) respectful reactions to their engagement, is likely to produce important practical knowledge as to how to influence group members to get actively involved in, and contribute to, the realization of their groups' goals.

\section{Notes}

1. The word fat is used here because it is the expression commonly used in the American fat acceptance movement.

2. The questionnaires also included items of the membership-esteem subscale of Luhtanen and Crocker's (1992) Collective Self-Esteem Scale. However, due to conceptual overlap with the respect concept, we did not include these items in the analyses presented below.

3. This distribution closely reflects the actual gender distribution in NAAFA.

4. To explore potential changes in the mean levels of the critical variables from Time 1 to Time 2 we also conducted a series of repeated measures analyses of variance. Results revealed that levels of importance-to-identity, private collective self-esteem and organizational participation remained fairly stable over time $(F \mathrm{~s} \leq 1.14$, $p s \geq .286)$. The mean level of perceived respect was higher at Time 1 than at Time $2(F(1,188)=$ $75.25, p<.001$ ) (Table 1).

\section{Acknowledgments}

This research was made possible by a grant from the Deutsche Forschungsgemeinschaft to Bernd Simon (Si 428/4-3). We are grateful to
Kathrin Maas for her assistance in conducting this study. We also thank Emanuele Castano and three anonymous reviewers for their valuable comments on our article

\section{References}

Branscombe, N. R., Spears, R., Ellemers, N., \& Doosje, B. (2002). Intragroup and intergroup evaluation effects on group behavior. Personality and Social Psychology Bulletin, 28, 744-753.

Brewer, M. B., \& Kramer, R. M. (1986). Choice behavior in social dilemmas: Effects of social identity, group size, and decision framing. Journal of Personality and Social Psychology, 50, 543-549.

Charng, H.-W., Piliavin, J. A., \& Callero, P. L. (1988). Role identity and reasoned action in the prediction of repeated behavior. Social Psychology Quarterly, 51, 303-317.

Clary, E. G., Snyder, M., Ridge, R. D., Copeland, J., Stukas, A. A., Haugen, J. et al. (1998). Understanding and assessing the motivations of volunteers: A functional approach. Journal of Personality and Social Psychology, 74, 1516-1530.

Cronbach, L. J., \& Furby, L. (1970). How we should measure 'change': Or should we? Psychological Bulletin, 74, 68-80.

De Weerd, M., \& Klandermans, B. (1999). Group identification and social protest: Farmers' protest in the Netherlands. European Journal of Social Psychology, 29, 1073-1095.

Ellemers, N., Kortekaas, P., \& Ouwerkerk, J. W. (1999). Self-categorization, commitment to the group and group self-esteem as related but distinct aspects of social identity. European Journal of Social Psychology, 29, 371-389.

Emler, N., \& Hopkins, N. (1990). Reputation, social identity and the self. In D. Abrams \& M. A. Hogg (Eds.), Social identity theory: Constructive and critical advances (pp. 113-131). New York: Springer.

Ethier, K. A., \& Deaux, K. (1994). Negotiating social identity when contexts change: Maintaining identification and responding to threat. Journal of Personality and Social Psychology, 67, 243-251.

Fullagar, C. (1986). A factor analytic study of the validity of a union commitment scale. Journal of Applied Psychology, 71, 129-136.

Haslam, S. A. (2001). Psychology in organizations. The social identity approach. Sage: London.

Heise, D. R. (1975). Causal analysis. New York: Wiley. 
Hogg, M. A., \& Abrams, D. (1996). Social identifications. A social psychology of intergroup relations and group processes. London: Routledge.

Hoyle, R. H. (ed.) (1995). Structural equation modeling: Concepts, issues, and applications. Newbury Park, CA: Sage.

Jackson, J. W. (2002). Intergroup attitudes as a function of different dimensions of group identification and perceived intergroup conflict. Self and Identity, 1, 11-33.

Jackson, J. W., \& Smith, E. R. (1999). Conceptualizing social identity: A new framework and evidence for the impact of different dimensions. Personality and Social Psychology Bulletin, 25, 120-135.

Kelly, C., \& Breinlinger, S. (1996). The social psychology of collective action: Identity, injustice and gender. London: Taylor \& Francis.

Kenny, D. A., Kashy, D. A., \& Bolger, N. (1998). Data analysis in social psychology. In D. T. Gilbert, S. T. Fiske, \& G. Lindzey (Eds.), The handbook of social psychology (4th ed., pp. 233-265). New York: Oxford University Press.

Klandermans, B. (1997). The social psychology of protest. Oxford: Basil Blackwell.

Kramer, R. M., \& Brewer, M. B. (1984). Effects of group identity on resource use in a simulated commons dilemma. Journal of Personality and Social Psychology, 46, 1044-1057.

Luhtanen, R., \& Crocker, J. (1992). A collective self-esteem scale: Self-evaluation of one's social identity. Personality and Social Psychology Bulletin, 18, 302-318.

Omoto, A. M., \& Crain, A. L. (1995). AIDS volunteerism: Lesbian and gay communitybased responses to HIV. In G. Herek \& B. Green (Eds.), Contemporary perspectives on lesbian and gay issues: Vol. 2. AIDS, identity, and community (pp.187-209). Thousand Oaks, CA: Sage.

Omoto, A. M., \& Snyder, M. (2002). Considerations of community: The context and process of volunteerism. American Behavioral Scientist, 45, 846-867.

Penner, L. A. (2002). Dispositional and organizational influences on sustained volunteerism: An interactionist perspective. Journal of Social Issues, 58, 447-467.

Rusbult, C. E., \& van Lange, P. A. M. (1996). Interdependence processes. In E. T. Higgings \& A. W. Kruglanski (Eds.), Social psychology: Handbook of basic principles (pp. 564-596). New York: Guilford.
Simon, B. (2004). Identity in modern society: A social psychological perspective. Blackwell: Oxford.

Simon, B., Loewy, M., Stürmer, S., Weber, U., Freytag, P., Habig, C. et al. (1998). Collective identification and social movement participation. Journal of Personality and Social Psychology, 74, 646-658.

Simon, B., Lücken, M., \& Stürmer, S. (2006). The added value of respect: Reaching across inequality. British Journal of Social Psychology, 45, 535-546.

Simon, B., \& Stürmer, S. (2003). Respect for group members: Intragroup determinants of collective identification and group-serving behavior. Personality and Social Psychology Bulletin, 29, 183-193.

Simon, B., \& Stürmer, S. (2005). In search of the active ingredients of respect: A closer look at the role of acceptance. European Journal of Social Psychology, 35, 809-818.

Simon, B., Stürmer, S., \& Steffens, K. (2000). Helping individuals or group members? The role of individual and collective identification in AIDS volunteerism. Personality and Social Psychology Bulletin, 26, 497-506.

Sleebos, E., Ellemers, N., \& de Gilder, D. (2006). The carrot and the stick: Respected and disrespected group members' motives to engage in group-serving efforts. Personality and Social Psychology Bulletin, 32, 244-255.

Smith, H. J., \& Tyler, T. R. (1997). Choosing the right pond: The influence of the status of one's group and one's status in that group on selfesteem and group-oriented behaviors. Journal of Experimental Social Psychology, 33, 146-170.

Smith, H., Tyler, T.R., Huo, Y. J., Ortiz, D. J., \& Lind, E. A. (1998). The self-relevant implications of the group-value model: Group membership, self-worth, and treatment quality. Journal of Experimental Social Psychology, 34, 470-493.

Stürmer, S. (2000). Soziale Bewegungsbeteiligung: Ein psychologisches Zwei-Wege Modell [Social movement participation: A psychological dual-pathway model]. Doctoral thesis, Faculty of Philosophy, ChristianAlbrechts-Universität zu Kiel.

Stürmer, S., \& Kampmeier, C. (2003). Active citizenship: The role of community identification in community volunteerism and local participation. Psychologica Belgica, 43, 103-122.

Stürmer, S., \& Simon, B. (2004). Collective action: Towards a dual-pathway model. In W. Stroebe \& M. Hewstone (Eds.), European review of social 
psychology (Vol. 15, pp. 59-99). Hove, UK: Psychology Press.

Stürmer, S., Simon, B., Loewy, M., \& Jörger, H. (2003). The dual-pathway model of social movement participation: The case of the fat acceptance movement. Social Psychology Quarterly, $66,71-82$.

Tajfel, H., \& Turner, J. C. (1986). The social identity theory of intergroup behavior. In S. Worchel \& W. G. Austin (Eds.), Psychology of intergroup relations (pp. 07-24). Chicago: Nelson-Hall.

Tropp, L. R., \& Brown, A. C. (2004). What benefits the group can also benefit the individual: Groupenhancing and individual-enhancing motives for collective action. Group Processes $\mathcal{E}$ Intergroup Relations, 7, 267-282.

Turner, J. C., Hogg, M. A., Oakes, P. J., Reicher, S. D., \& Wetherell, M. S. (1987). Rediscovering the social group: A self-categorization theory. Oxford, UK: Blackwell.

Tyler, T. R., \& Blader, S. (2000). Cooperation in groups: Procedural justice, social identity, and behavioral engagement. Philadelphia: Psychology Press.

Tyler, T. R., Degoey, P., \& Smith, H. (1996). Understanding why the justice of group procedures matters: A test of the psychological dynamics of the group-value model. Journal of Personality and Social Psychology, 70, 913-930.

Tyler, T. R., \& Smith, H. J. (1999). Justice, social identity, and group processes. In T. R. Tyler, R. M. Kramer, \& O. P. John (Eds.), The psychology of the social self (pp. 223-264). Mahwah, NJ: Erlbaum.

van Dick, R., Wagner, U., Stellmacher, J., \& Christ, O. (2004). The utility of a broader conceptualization of organizational identification: Which aspects really matter?
Journal of Occupation and Organizational Psychology, 77, 171-191.

van Vugt, M., \& De Cremer, D. (1999). Leadership in social dilemmas: The effect of group identification on collective actions to provide public goods. Journal of Personality and Social Psychology, 76, 587-599.

Wenzel, M. (2004). A social categorization approach to distributive justice. European Review of Social Psychology, 15, 219-257.

Paper received 9 August 2005; revised version accepted 14 May 2007.

\section{Biographical notes}

STEFAN STÜRMER is professor of social psychology at the FernUniversität in Hagen (Germany). His research focuses on the role of group processes in social movement participation, cooperation, helping and altruism.

BERND SIMON is professor of social psychology and evaluation research at the Christian-AlbrechtsUniversity in Kiel (Germany). In his research, he investigates inter- and intragroup processes, with particular emphasis on issues of identity, power, politicization and respect.

MICHAEL I. LOEWY is associate professor and chair of the department of counseling psychology and community services at the University of North Dakota in Grand Forks. His research focuses on the social psychological implications of group identity and participation in social movements, and on the clinical applications of size acceptance, fear of fat and the causes and treatments of poor body image. 